\title{
Stabilization Appliances as Treatment for Myogenous Temporomandibular Disorders: A Systematic Review and Meta-analysis
}

\author{
Jon Delsnyder ${ }^{1}$, Thomas Colina ${ }^{1}$, Nagy Elsemary ${ }^{1}$, Mariela Padilla $^{2}$, Reyes Enciso ${ }^{3, *}$ \\ ${ }^{1}$ Science Program in Orofacial Pain and Oral Medicine, Herman Ostrow School of Dentistry, University of Southern California, USA \\ ${ }^{2}$ Division of Periodontology, Diagnostic Sciences and Dental Hygiene, Herman Ostrow School of Dentistry, \\ University of Southern California, USA \\ ${ }^{3}$ Division of Dental Public Health and Pediatric Dentistry, Herman Ostrow School of Dentistry, University of Southern California, USA
}

Copyright $\mathrm{O} 2017$ by authors, all rights reserved. Authors agree that this article remains permanently open access under the terms of the Creative Commons Attribution License 4.0 International License

\begin{abstract}
The objective of this study was to determine if the use of flat stabilization appliances would benefit patients with myogenous temporomandibular disorders. Methods. The studies chosen were randomized controlled trials which evaluated flat plane stabilization splints (SS) versus non-occluding palatal splints (NOS) for the treatment of myogenous temporomandibular disorders. The Cochrane Library, Medline through PubMed and Web of Science were searched for studies which met the criteria mentioned above. Results. Review authors assessed 544 unduplicated references which were reduced to eight randomized controlled clinical trials. Four were assessed at unclear risk of bias and four were at high risk. Patients wearing a flat plane stabilization splint only at night had a significantly better reduction in pain intensity $(\mathrm{p}=.015)$, and the subjects had a greater chance to have a $50 \%$ or more of reduction of pain intensity $(\mathrm{p}=.037)$ than patients wearing a non-occluding splint. However, there were no statistically significant differences between SS worn 24 hours a day and a non-occluding splint in reduction of pain intensity $(\mathrm{p}=.646)$ or number of responders to treatment $(p=.323)$. There were no significant differences detected between SS (worn at night or 24 hours a day) and NOS in any of the other outcomes measured (tenderness of muscles of mastication at palpation, interincisal opening or clicking). Conclusions. There is low quality of evidence to support the use of flat stabilization splints worn only at night or 24 hours to provide a reduction of pain intensity in the treatment for myogenous temporomandibular disorders. Large RCTs with lower risk of bias and standardized methodology comparing stabilization splints to non-occluding splints are needed to confirm these results.
\end{abstract}

Keywords Myogenous, Temporomandibular Disorder, Stabilization Splint, Non-occluding Splint, Randomized
Controlled Studies, Meta-analysis

\section{Introduction}

Temporomandibular joint disorders (TMD) are a heterogeneous group of conditions that can affect the temporomandibular joint (TMJ), disc and/or the supporting muscles of the TMJ [1]. According to the OPPERA study [1, 2] TMD affects $5 \%$ of the general population, with women suffering twice as often as men. The Diagnostic Criteria for Temporomandibular Disorders (DC/TMD) [3] divides TMD into 3 taxonomic classifications: 1) Temporomandibular joint disorders, 2) Masticatory muscle disorders, and 3) Headaches attributed to TMD. The DC/TMD lists the most common masticatory muscle disorders [or myogenous disorders] as local myalgia, myofascial pain and myofascial pain with referral. Prior to 2014, most research studies utilized the diagnostic criteria set out in the Research Diagnostic Criteria for Temporomandibular Disorders (RDC/TMD) [4]. The RDC/TMD divided TMD's into three groups: muscle disorders, disc displacements and arthralgia conditions. Muscle disorders were then subdivided into myofascial pain and myofascial pain with limited opening [4]. Myofascial pain is defined based on two criteria, 1) report of pain or ache in the jaw, temples, face, pre-auricular area or inside the ear at rest or during function and 2) pain reported by the subject in response to palpation of three or more of 20 muscle sites [4]. In 1996, the AAOP published guidelines for classification, assessment, and management of TMD [5]. These guidelines divided conditions into temporomandibular disorders and masticatory muscle disorders. Most of the studies included in this review utilized the diagnostic criteria laid out in the RDC/TMD [4]. 
Myogenous (muscle related) TMD represents the most common orofacial pain complaint and occurs in about $80 \%$ of all TMD patients [6]. Dentists are the front-line clinicians dealing with this condition [1]. The therapeutic effect of stabilization appliances remains elusive and not fully understood, yet they are by far, the most common treatment modality utilized by dentists for temporomandibular disorders [6,7]. They are a conservative, reversible and inexpensive treatment [8] for a condition which causes significant impairment to a person's quality of life [7].

In 2010, in a systematic review (SR) of the most current published SRs at that time by List and Axelsson [9], the authors stated that one limitation of most of the reviewed SRs was that the considerable variation in methodology between the primary studies made definitive conclusions impossible. Fricton et al. [10] reinforces this by suggesting that more studies with consistent methodology are needed for definitive conclusions of the efficacy of different types of appliances and their comparative effectiveness relative to other common TMD treatments.

The objective of this SR was to determine the efficacy of a flat plane stabilization appliance (treatment) when treating patients with myogenous temporomandibular pain versus a non-occluding sham appliance (control). This SR presents the first meta-analyses that isolates the intervention (stabilizing splint), compared to a control (non-occluding splint) in the treatment of a specific TMD classification (myogenous TMD). The authors' aim was to derive very specific conclusions on the efficacy of stabilization splints in the treatment of myogenous TMD.

\section{Materials and Methods}

\subsection{Inclusion and Exclusion Criteria}

Studies were limited to randomized controlled trials (RCTs) evaluating the effectiveness of flat plane stabilization appliance to reduce myogenous temporomandibular pain in comparison to non-occluding sham splints. The appliances included in our study were hard acrylic flat plane stabilization splints covering all teeth on either arch for the treatment group and acrylic palatal devices that did not cover the occlusal surface for the control group.

Studies were limited to myogenous temporomandibular disorders as described in the RDC/TMD [4], or the DC/TMD [3] or as defined by the American Academy of Orofacial Pain (AAOP) [5]. All of the studies except one [11] utilized the RDC/TMD [4] criteria to define myogenous TMD. Alencar et al. [11] utilized the criteria set out in 1996 by the AAOP [5]. Studies including patients with degenerative disc disorders or arthralgia were excluded as were studies including headache patients attributed to TMD. Opinion letters, editorials, commentaries, conference abstracts, reviews, systematic reviews, case studies, animal studies, cost-effectiveness studies, pharmacokinetic studies, and guidelines were omitted. Articles not available in English were also omitted.

Three review authors (T.C., J.D. and N.E) individually assessed trial reports to determine their eligibility. Disagreements to include or exclude a reference were resolved by discussion with a 4th review author acting as moderator (R.E.) Inclusion criteria included studies of patients 18 years and older, suffering from myogenous TMD. The stabilization splints (SS) and non-occluding splints (NOS) were provided for patients in the treatment group and control group respectively. Each study had to have at least one clinical endpoint whether it being pain reduction using the visual analog scale (VAS) or another established form of pain measurement. Secondary outcomes were unassisted maximum opening, the number of tender muscles at palpation and the number of responders to treatment.

\subsection{Search Methods for Identification of Studies.}

The following electronic databases were searched:

MEDLINE via PubMed (searched on 3/10/2016; updated on 2/16/2017). PubMed Search strategy limited to humans and the English language: ("Occlusal Splints"[Mesh] OR "stabilization splint"[All Fields] OR "night guard"[All Fields] OR "oral appliance"[All Fields] OR nightguard [All Fields] OR "intraoral splint*"[All Fields]) AND ("Temporomandibular Joint Disorders/prevention and control"[Mesh] OR "Temporomandibular Joint Disorders/therapy"[Mesh] OR "myofascial pain"[All Fields] OR "arthralgia"[MeSH Terms] OR capsulitis[All Fields] OR "myalgia"[MeSH Terms] OR ("temporomandibular joint"[MeSH Terms] OR ("temporomandibular"[All Fields] AND "joint"[All Fields]) OR "temporomandibular joint"[All Fields] OR "tmj"[All Fields]) OR "orofacial pain"[All Fields] OR "degenerative joint disease"[All Fields] OR "facial pain"[All Fields] OR "craniomandibular disorders"[All Fields] OR "myalgia"[All Fields]) AND ((systematic[sb] OR Clinical Trial[ptyp] OR Randomized Controlled Trial[ptyp] OR Review[ptyp]) AND "humans"[MeSH Terms] AND English[lang]).

The Web of Science (searched on 3/10/2016; updated on 2/16/2017) search strategy: TOPIC (Occlusal Splint OR stabilization splint OR nightguard OR oral appliance OR orthotic OR splint* OR Appliance OR intraoral splint* OR device) AND TOPIC (Temporomandibular Joint Disorder* OR myofascial pain OR arthralgia OR capsulitis OR myalgia OR temporomandibular joint OR tmj OR orofacial pain OR degenerative joint disease OR facial pain OR craniomandibular disorder* OR myalgia) AND TOPIC Random*

The Cochrane Library (searched on 3/10/2016; updated on 2/16/2017) search strategy: \#1. (Occlusal Splint OR stabilization splint OR nightguard OR oral appliance OR intraoral splint*). \#2. (Temporomandibular Joint Disorder* OR myofascial pain OR arthralgia OR capsulitis OR myalgia OR temporomandibular joint OR tmj OR orofacial pain OR 
degenerative joint disease $\mathrm{OR}$ facial pain $\mathrm{OR}$ craniomandibular disorder* OR myalgia). \#3. Random*. \#4. \#1 AND \#2 AND \#3.

\subsection{Data Collection and Analysis. Selection of Studies}

Three reviewers (T.C., J.D., N.E.) individually assessed trial reports to determine eligibility based on inclusion/exclusion criteria. Reviews, systematic reviews, clinical guidelines and eligible RCTs were scanned for relevant studies. Abstracts were initially reviewed to determine if the full text article should be obtained. If the article seemed to fulfill the criteria or the authors were unable to decide regarding inclusion, a full text article would be obtained and evaluated by each reviewer.

\subsection{Data Extraction and Management. Assessment of Risk of Bias}

The same three reviewers individually extracted the data from the full text articles which were eligible for inclusion. The data included the number and demographics of the participants as well as intervention method, treatment groups, control groups and outcomes. The reviewers used the risk of bias tool according to the methods described in Cochrane Handbook for Systematic Reviews of Interventions [12]. A fourth reviewer (R.E) helped resolve any disagreements or concerns the authors had.

\subsection{Measures of Treatment Effect}

Paired meta-analyses were conducted for trials reporting similar outcome measures for similar interventions (SS versus control). Cochran's $Q$ test [13] and the $I^{2}$ statistic [14] were used to test for statistical heterogeneity. If heterogeneity was found $(\mathrm{Q} P$-value $<.10)$ or less than studies were available for analysis, estimates of effect were combined using a random-effects model; otherwise, the fixed-effects model was applied. Standardized difference in means (SDM) were calculated with $95 \% \mathrm{CI}$ for the change in pain intensity (VAS) and degree of tenderness of muscles. Subgroup analyses are shown for trials using splints worn 24 hours a day and splints worn only at night. Risk Ratios (RR) were calculated for responders to treatment and clicking with same subgroup analyses as above. Statistical analyses were conducted with Comprehensive Meta-Analysis Software Version 3 (Biostat, USA).
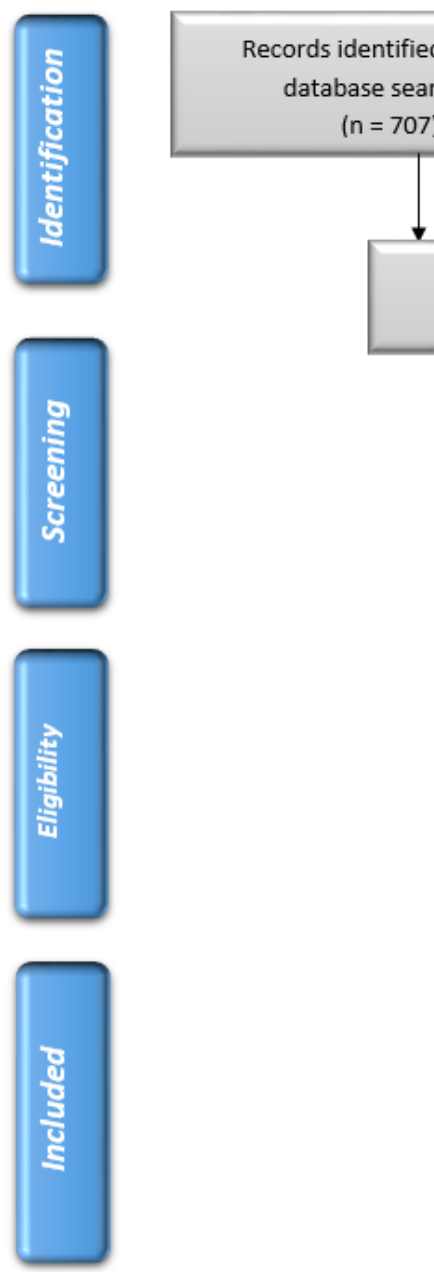

Additional records identified through other sources $(n=2)$

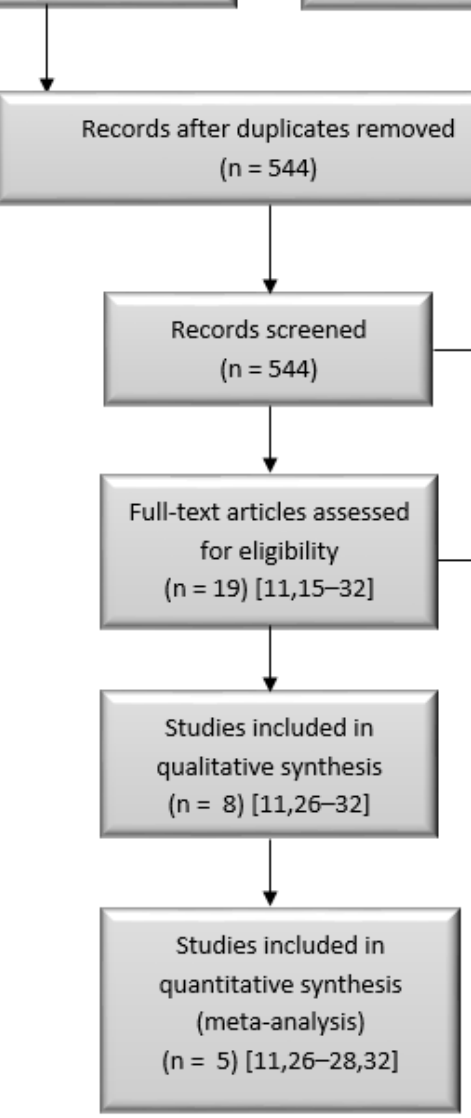

Figure 1. PRISMA Flowchart Diagram 


\section{Results}

\subsection{Results of the Search}

The initial search strategy yielded 707 references (including duplicates) and 2 additional records identified through other sources (scanning of reference section of included studies and reviews and systematic reviews). From these, 544 unduplicated references were assessed independently by three review authors, and based on the abstracts and titles these were reduced to 19 relevant manuscripts.

Reasons for exclusion of those 525 references were: the article was a review $(n=14)$, systematic review $(n=17)$, book chapter $(n=6)$, opinion/editorial $(n=41)$, not a randomized controlled trial $(n=14)$, different condition $(n=294)$, different intervention ( $n=73)$, different outcome $(n=16)$, not in English $(n=5)$, animal studies $(n=21)$, in children $(n=4)$, case study or case report $(n=5)$, protocol of a RCT or review $(n=4)$, different control group $(n=10)$ and pilot study $(n=1)$.

Full text articles were obtained of the 19 identified as eligible, based on the title and abstract. These manuscripts were analyzed independently for inclusion by three authors (J.D., T.C., N.E.). There were 11 articles excluded after full text review [15-25]. Reasons for exclusion were as follows: two had no splint in the control group $[15,16]$, one had an anterior midline point stop splint [17], one had a prefabricated oral appliance [18], two were not randomized control trials $[19,20]$, one had different outcomes such as headaches [21] and four included patients with different conditions such as migraine patients with TMD [22], muscular and TMJ pain [23, 24] and otalgia [25]. PRISMA flowchart shows a summary of our search results (Figure 1).
Eight studies were eligible for qualitative analysis [11, 26-32] as shown in Table 1. Studies included in this review were RCTs where occlusal appliances (full arch flat plane stabilization splints in either arch) were compared to a sham treatment (non-occluding splints) for patients with myogenous TMD. One study [29] was a long term follow up of a prior study [28]. All studies [11, 26-32] were one center studies. The number of participants ranged from a minimum of 28 in one study [27] to 68 participants in another study [30]. Two studies [30, 31] included women participants only. The common inclusion criteria for all the studies was myofascial pain as defined by the American Academy of Orofacial Pain (AAOP) in 1996 for one study [11] or the RDC/TMD [26-32]. Other common inclusion criteria were adequate number of teeth to retain the appliance. Two studies included pain duration in their inclusion criteria, 12 weeks in one study [26] and at least 6 months in one study [32]. Seven studies [26-32] compared hard acrylic stabilization splint to non-occluding splint control groups, while one study [11] compared groups treated with hard acrylic stabilization splint, soft splint and a non-occluding splint. The duration of the studies ranged from four weeks [32] to 90 days [11]. Three studies had the participants wear the splint for 24 hours [26, $27,32]$ and five had the participants only wear the appliance at night [11, 28-31]. Unfortunately, not all the studies reported the same outcomes; of the eight studies [11, 26-32] included in the qualitative review, only five [11, 26-28, 32] could be included in the meta-analyses (Figure 1). The common primary outcomes included change in VAS [27-29, $32]$, change in number of muscle tenderness [11, 27-29], change in pain intensity [11, 26, 28, 29, 32], and clicking [27-29]. Four studies assessed functional changes [28-30, 32].

\subsection{Included Studies}

Table 1. Summary of eligible RCT studies. SS = Stabilization appliance; NOS = Non-occluding splint.

\begin{tabular}{|c|c|c|c|c|}
\hline Reference & $\begin{array}{c}\text { Year/ } \\
\text { Country }\end{array}$ & $\begin{array}{l}\text { Interventions/ } \\
\text { sample size }\end{array}$ & Inclusion criteria & Summary \\
\hline $\begin{array}{c}\text { Alencar \& Becker } \\
2009[11]\end{array}$ & $\begin{array}{c}2009 \\
\text { Brazil } \\
\mathrm{N}=42\end{array}$ & $\begin{array}{l}\text { Hard SS }(n=14) \\
\text { Soft SS }(n=14) \\
\text { NOS }(n=14)\end{array}$ & $\begin{array}{l}\text { (1) Patients diagnosed with myofascial pain based on } \\
\text { Diagnostic Criteria of the American Academy of } \\
\text { Orofacial Pain (AAOP)[5] with reproduction of the chief } \\
\text { complaint with palpation of a trigger point in the } \\
\text { masseter muscle; } \\
\text { (2) } 18-65 \text { years old and } \\
\text { (3) Having at least six natural teeth in each quadrant. }\end{array}$ & Unclear \\
\hline Dao et al. 1994 [26] & $\begin{array}{c}1994, \\
\text { Canada } \\
\mathrm{N}=63\end{array}$ & $\begin{array}{c}\text { SS worn } 24 \text { hours }(n=22) \\
\text { NOS worn } 24 \text { hours }(n=20) \\
\text { SS worn } 30 \text { minutes x } 7 \\
\text { times }(n=21)\end{array}$ & $\begin{array}{l}\text { 1. men or women ranging in age from } 16 \text { to } 45 \text { and } \\
\text { seeking treatment; } \\
\text { 2. chief complaint of frequent pain (at least } 4 \\
\text { times/week) in the jaw muscles of at least } 12 \text { weeks } \\
\text { duration } \\
\text { 3. positive report of tenderness to palpation of at least } 3 \\
\text { sites in the masticatory muscles [4] }\end{array}$ & High \\
\hline $\begin{array}{c}\text { Ekberg et al. } 2003 \\
{[28]}\end{array}$ & $\begin{array}{c}2003 \\
\text { Sweden } \\
\mathrm{N}=60\end{array}$ & $\begin{array}{c}\text { SS }(n=30) \\
\text { NOS }(n=30)\end{array}$ & $\begin{array}{l}\text { Pain of muscular origin with or without limited opening, } \\
\text { including a complaint of pain associated with localized } \\
\text { areas of tenderness to palpation in masticatory muscles, } \\
\text { combined with self-assessed myofascial pain of at least } \\
40 \mathrm{~mm} \text { on a } 100 \text {-mm visual analog scale (VAS) } \\
\text { The clinical diagnosis was myofascial pain with or with- } \\
\text { out limited opening according to the Research } \\
\text { Diagnostic Criteria for TMD[4] }\end{array}$ & Unclear \\
\hline
\end{tabular}




\begin{tabular}{|c|c|c|c|c|}
\hline $\begin{array}{c}\text { Ekberg \& Nilner, } \\
2004 \text { [29] }\end{array}$ & $\begin{array}{c}2004 \\
\text { Sweden } \\
\mathrm{N}=60\end{array}$ & $\begin{array}{c}\text { SS }(n=30) \\
\text { NOS }(n=30)\end{array}$ & Follow-up study of Ekberg et al. 2003 [28]. & High \\
\hline $\begin{array}{c}\text { Raphael \& Marback, } \\
2001[30]\end{array}$ & $\begin{array}{c}2001 \\
\mathrm{U} . \mathrm{S} \\
\mathrm{N}=68\end{array}$ & $\begin{array}{c}\text { SS }(n=35) \\
\text { NOS }(n=33)\end{array}$ & $\begin{array}{l}\text { (1) Patients had to meet criteria for the myofascial } \\
\text { subtype of TMD based on the Research Diagnostic } \\
\text { Criteria in which facial pain associated with localized } \\
\text { tenderness in response to palpation at three or more of } 20 \\
\text { muscle sites. } \\
\text { (2) Patients meeting criteria for other TMDs, such as } \\
\text { osteoarthritis of the temporomandibular joint, were not } \\
\text { automatically excluded, provided that their chief } \\
\text { complaint was pain (as opposed to clicking or difficulty } \\
\text { opening their mouths). To deem eligible a prospective } \\
\text { subject who had additional comorbid TMD conditions, } \\
\text { we had to make a clinical judgment that the pain was } \\
\text { primarily myofascial. } \\
\text { (3) Only women were enrolled; } \\
\text { (4) Subjects were required to be fluent in English, } \\
\text { although English did not have to be their first language. } \\
\text { (5) Required to have at least six maxillary and six } \\
\text { mandibular posterior natural teeth that occluded. } \\
\text { *Participating patients met criteria for the myofascial } \\
\text { subtype of TMD according to the research diagnostic } \\
\text { criteria, or RDC/TMD[4] }\end{array}$ & High \\
\hline $\begin{array}{c}\text { Raphael \& Marback, } \\
2003[31]\end{array}$ & $\begin{array}{c}2003, \\
\text { USA } \\
\mathrm{N}=68\end{array}$ & $\begin{array}{l}\mathrm{SS}(\mathrm{n}=35 \text { started; } 24 \text { finished }) \\
\text { NOS ( } \mathrm{n}=33 \text { started; } \mathrm{n}=28 \\
\text { finished })\end{array}$ & $\begin{array}{c}\text { Follow-up of Raphael \& Marback, [30]. } \\
\text { *Participating MFP patients had to meet criteria for the } \\
\text { myofascial subtype of TMD based on the Research } \\
\text { Diagnostic Criteria (RDC) [4] }\end{array}$ & High \\
\hline $\begin{array}{c}\text { Rubinoff et al. } \\
\text { 1987[27] }\end{array}$ & $\begin{array}{c}1987, \\
\text { USA } \\
\mathrm{N}=28\end{array}$ & $\begin{array}{l}\text { 1. SS } 24 \text { hours }(n=15) \\
\text { 2. } \operatorname{NOS}(n=13)\end{array}$ & $\begin{array}{l}\text { Complaint of facial pain and one or more of the } \\
\text { following: limited opening, joint sounds, deviation on } \\
\text { opening, and tenderness to muscle palpation. In addition, } \\
\text { it was required that both clinical and radiographic } \\
\text { assessment demonstrate absence of organic pathologic } \\
\text { condition of the temporomandibular joint (TMJ). } \\
\text { Participants were required only to have enough } \\
\text { maxillary teeth to retain an appliance without clasping }\end{array}$ & Unclear \\
\hline $\begin{array}{c}\text { Zhang et al. } 2013 \\
\text { [32] }\end{array}$ & $\begin{array}{l}2013 \\
\text { China } \\
\mathrm{N}=36\end{array}$ & $\begin{array}{l}\text { SS } 24 \text { hours }(\mathrm{n}=18) \\
\text { NOS }(\mathrm{n}=18)\end{array}$ & $\begin{array}{l}\text { (1) Painful unilateral masseter myofascial pain; (2) } \\
\text { diagnosed as chronic pain (pain greater than } 6 \text { months). } \\
\text { The largest reported pain period was } 3 \text { years. } \\
\text { *“Eligible subjects were patients who presented with a } \\
\text { major complaint of painful unilateral TMD and } \\
\text { diagnosed as chronic pain Axis I[4] }\end{array}$ & Unclear \\
\hline
\end{tabular}

Table 2. Summary of risk of bias for eligible RCT studies. + High risk; - Low risk;? Unclear risk

\begin{tabular}{|c|c|c|c|c|c|c|c|}
\hline Study & $\begin{array}{c}\text { Random Seq. } \\
\text { Generation }\end{array}$ & $\begin{array}{c}\text { Allocation } \\
\text { Concealment }\end{array}$ & Blinding & $\begin{array}{c}\text { Incomplete } \\
\text { Outcome Data }\end{array}$ & $\begin{array}{c}\text { Selective } \\
\text { Reporting }\end{array}$ & $\begin{array}{c}\text { Other } \\
\text { potential bias }\end{array}$ & $\begin{array}{c}\text { Overall } \\
\text { Bias }\end{array}$ \\
\hline Alencar \& Becker, 2009[11] & $?$ & $?$ & $?$ & - & - & $?$ & $?$ \\
\hline Dao et al. 1994[26] & + & + & $?$ & $?$ & - & + & + \\
\hline Ekberg et al. 2003[28] & - & - & $?$ & - & - & $?$ & $?$ \\
\hline Ekberg \& Nilner, 2004[29] & + & + & + & - & - & $?$ & + \\
\hline Raphael \& Marback, 2001[30] & $?$ & $?$ & $?$ & $?$ & - & + & + \\
\hline Raphael \& Marback, 2003[31] & $?$ & $?$ & $?$ & + & - & + & + \\
\hline Rubinoff et al. 1987[27] & $?$ & $?$ & $?$ & $?$ & - & - & $?$ \\
\hline Zhang et al. 2013[32] & - & $?$ & $?$ & - & - & - & $?$ \\
\hline
\end{tabular}

\subsection{Risk of Bias in Included Studies}

In the eight articles evaluated the authors analyzed the risk of bias based on low risk, high risk and unclear risk. Table 2 lists the risks for randomization, allocation concealment, blinding, incomplete outcome data and selective reporting.

\subsubsection{Random Sequence Generation}

Of the eight studies, two studies $[28,32]$ were considered at low risk for random sequence generation bias. Techniques used to generate the randomization included block randomization, random envelope selection and a random digit table. Four of the studies $[11,27,30,31]$ were assessed 
at unclear risk because although the authors indicated that the studies were randomized, there was no mention of how the randomization was done. Two of the studies [26, 29] were considered high risk due to participants not remaining in their assigned groups.

\subsubsection{Allocation Concealment}

One of the studies [28] was low risk because the information regarding who was in the treatment group and who was in the control groups was placed in sealed envelopes prior to initiation of the study. Five of the studies [11, 27, 30-32] did not indicate the method of allocation concealment and were considered of unclear risk. Two of the studies were categorized as high risk because there was no concealment or it was inadequate $[26,29]$ and participants in one study were moved from the control group into a treatment group [26].

\subsubsection{Blinding}

The studies were effective in blinding the subjects, however none of the studies effectively outlined how they blinded all four (subjects, investigators delivering the appliances, data assessors, data analysts); therefore, zero studies were considered low risk. Seven studies [11, 27-32] were of unclear risk because it is difficult, if not impossible to completely blind the researcher who delivers and adjusts the appliances and most of these studies did not indicate how the outcome assessors were blinded. One study [26] was considered high risk of bias because the subjects did not remain in the control groups and were switched to treatment groups.

\subsubsection{Incomplete Outcome Data}

Four studies [11, 28, 29, 32] contained no missing data and were considered low risk for bias. Three of the papers $[26,27,30]$ were deemed of unclear risk because even though dropouts were low, an intention to treat analysis was not presented. One study [31] was high risk due to the high number of dropouts in the trial and no intention to treat analysis.

\subsubsection{Selective Reporting}

All the outcomes listed in the studies were reported [11, 26-32], so there was a low risk of bias in relation to selective reporting.

\subsubsection{Other Bias}

Other forms of bias analyzed were funding sources, co-interventions, unbalanced groups etc. Two of the reviewed papers $[27,32]$ were considered low risk for these biases because the studies were appropriately funded by non-biased, non-questionable funding sources, they had no reported co-interventions and all groups were balanced at baseline. Three of the studies were considered of unclear risk because two of them $[11,29]$ had co-interventions as part of the study and one [28] had slightly unbalanced groups at baseline. Three trials $[26,30,31]$ had a high risk of bias due to participants using significant co-interventions during the study.

\subsubsection{Overall Risk of Bias}

In summary, none of the research papers were considered to have low overall risk for bias. Four were assessed at unclear risk [11, 27, 28, 32] while four were assessed at high risk of bias [26, 29-31] (Table 2; Figure 2).

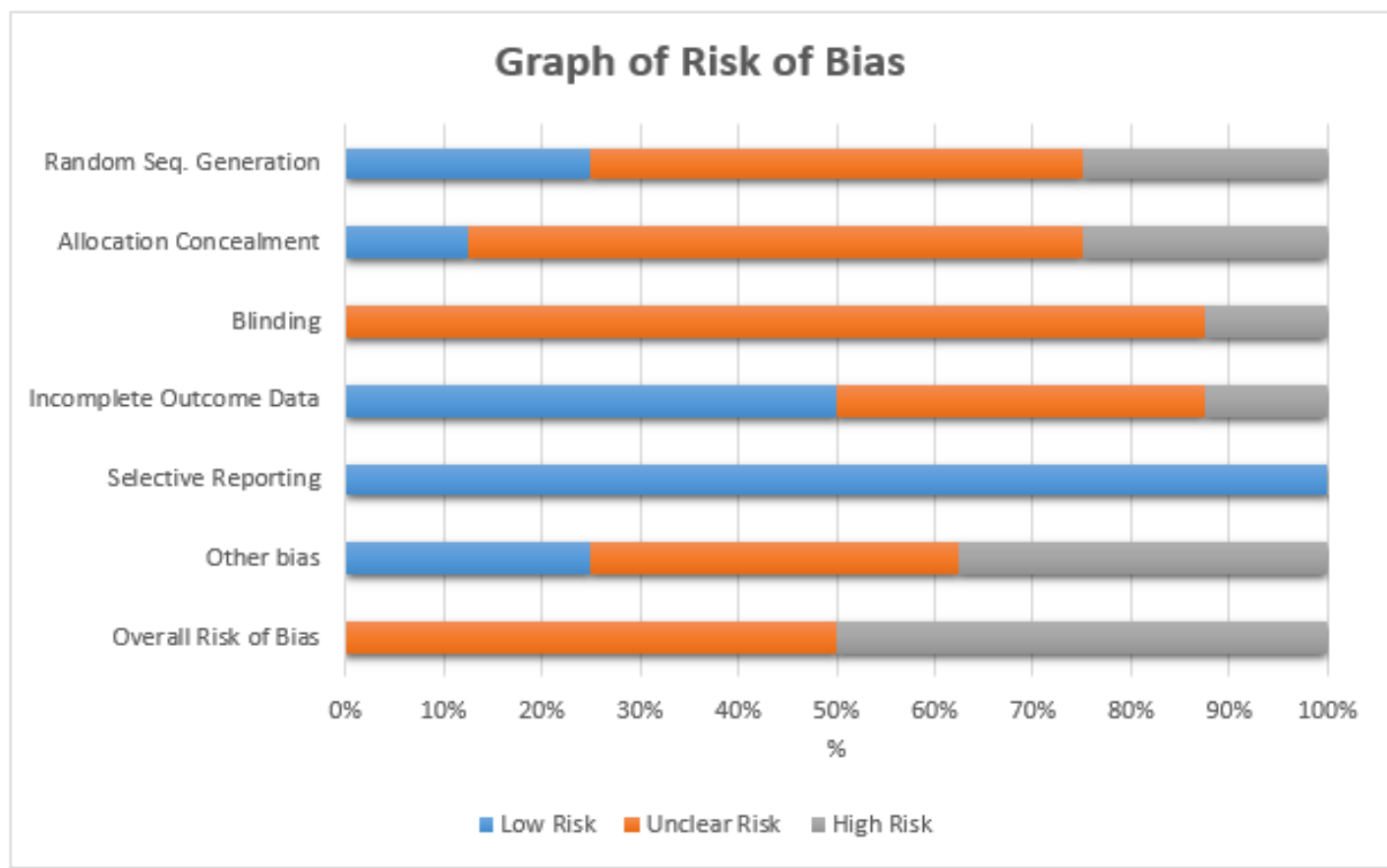

Figure 2. Graph of risk of bias for included studies 


\subsection{Effects of Interventions (Meta-Analyses)}

Of the eight eligible RCTs comparing stabilizing splints to non-occluding splints, only five [11, 26-28, 32] studies reported similar outcomes and could be included in the meta-analyses (Figure 1). Three of the studies [26, 27, 32] had the patients wear their appliances for 24 hours a day, while two of the studies $[11,28]$ had the participants wear the appliances only at night; meta-analyses were reported for each subgroup (appliances worn at night or 24 hours a day).

Change in pain intensity (VAS): Three studies reported mean and standard deviation (SD) of pain intensity at baseline and post-treatment, one only worn at night [28] and two worn for 24 hours [27,32] Statistically significant heterogeneity was found for the two studies reporting splints worn 24 hours [27, 32] $(\mathrm{Q} p<.001 ; \mathrm{I} 2=94 \%)$. The reduction in pain intensity (VAS) with a SS worn only at night [28] was statistically significantly better compared to a NOS (fixed effects: $\mathrm{SDM}=-0.646 ; 95 \% \mathrm{CI}=-1.165$ to $-0.127 ; \mathrm{p}=.015$ ), however the SS worn 24 hours a day showed no significant difference with NOS (random effects: $\mathrm{SDM}=-0.508 ; 95 \%$ $\mathrm{CI}=-2.671$ to $1.656 ; \mathrm{p}=.646)$ (Figure 3 ).

Interincisal opening: Only one study [27] reported mean and SD of maximum unassisted mouth opening at baseline and post-treatment. No significant difference was found in interincisal opening after SS therapy compared to NOS ( $p$ $=.637$ ).

Degree of tenderness of the muscles of mastication at palpation: Three studies $[11,27,28]$ reported degree of tenderness of muscles of mastication on a scale $0-3$. In two of the studies $[11,28]$ the SS was worn at night only, and no significant heterogeneity was found among those two studies (I2 $=0 \%$ ). In one study, it was worn 24 hours a day [27]. There was no statistically significant difference between the SS and the NOS in the change in muscles of mastication's tenderness in either the 24 hours study $(p=417)$ nor the night-only studies ( $\mathrm{p}=.175)$ (Figure 4).

Responders to treatment: Three studies [26-28] reported the number of patients with $50 \%$ or more of reduction of pain intensity. Patients wearing a SS at night only [28] had a significantly higher chance of being responders to treatment than patients receiving a $\mathrm{NOS}(\mathrm{RR}=2.600 ; 95 \% \mathrm{CI}=1.058$ to $6.387 ; \mathrm{p}=.037$ ), however no significant difference was found when comparing wearing a splint for 24 hours $[26,27]$ to a $\operatorname{NOS}(\mathrm{RR}=0.748 ; 95 \% \mathrm{CI}=0.421$ to $1.330 ; \mathrm{p}=.323)$ (Figure 5).

Change in pain intensity (VAS)

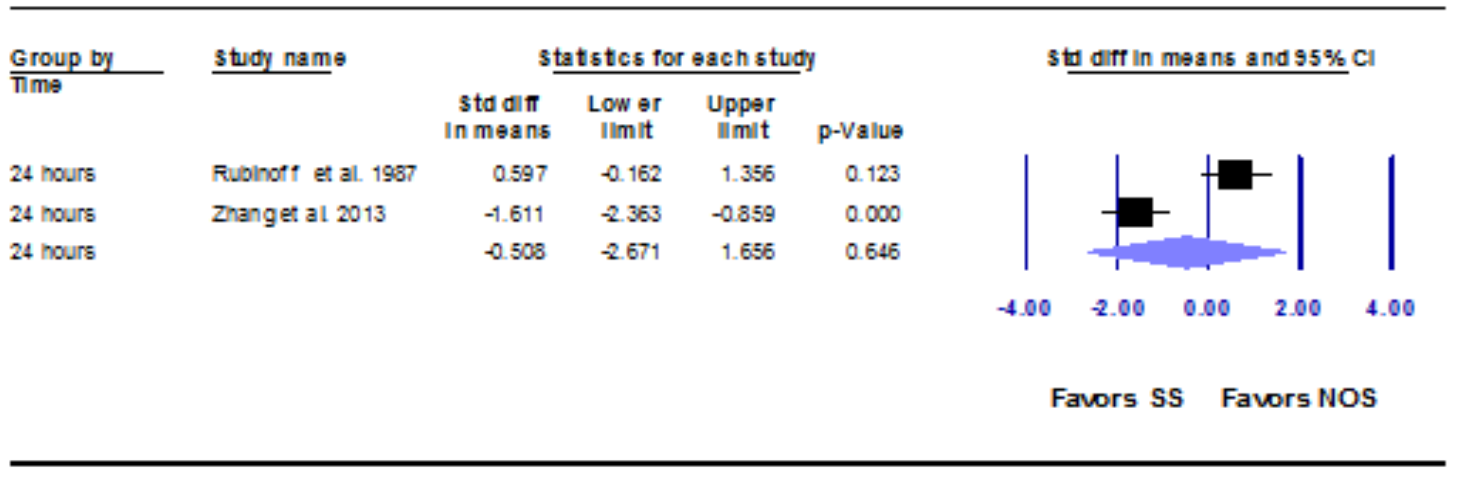

Change in pain intensity (VAS)

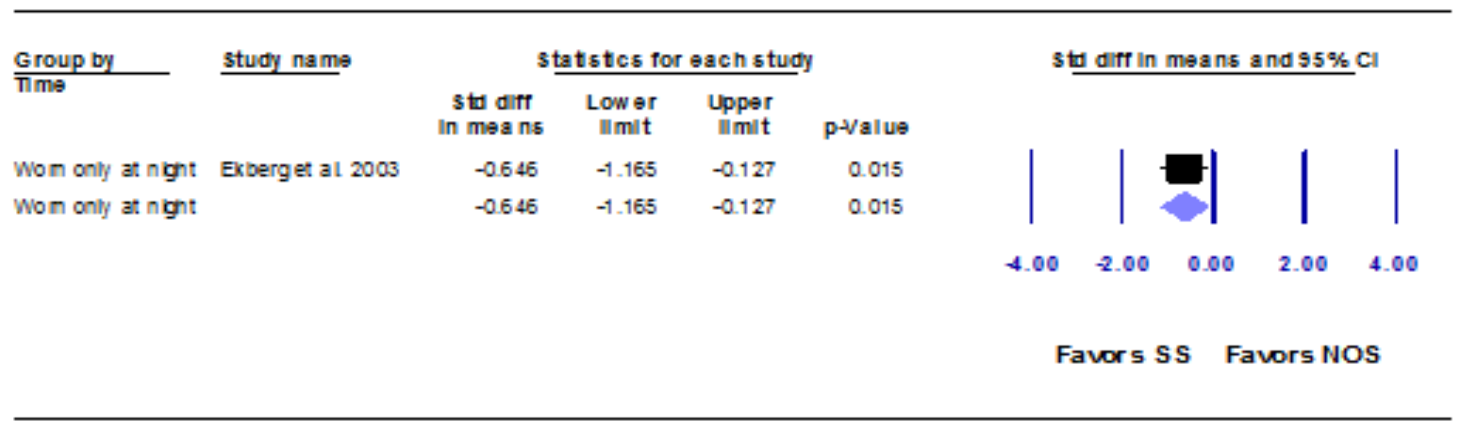

Figure 3. Stabilization splint versus non-occluding splint in the treatment of myofascial pain patients: change in intensity of pain (VAS) with treatment. 


\section{Tenderness of muscles of mastication at palpation}

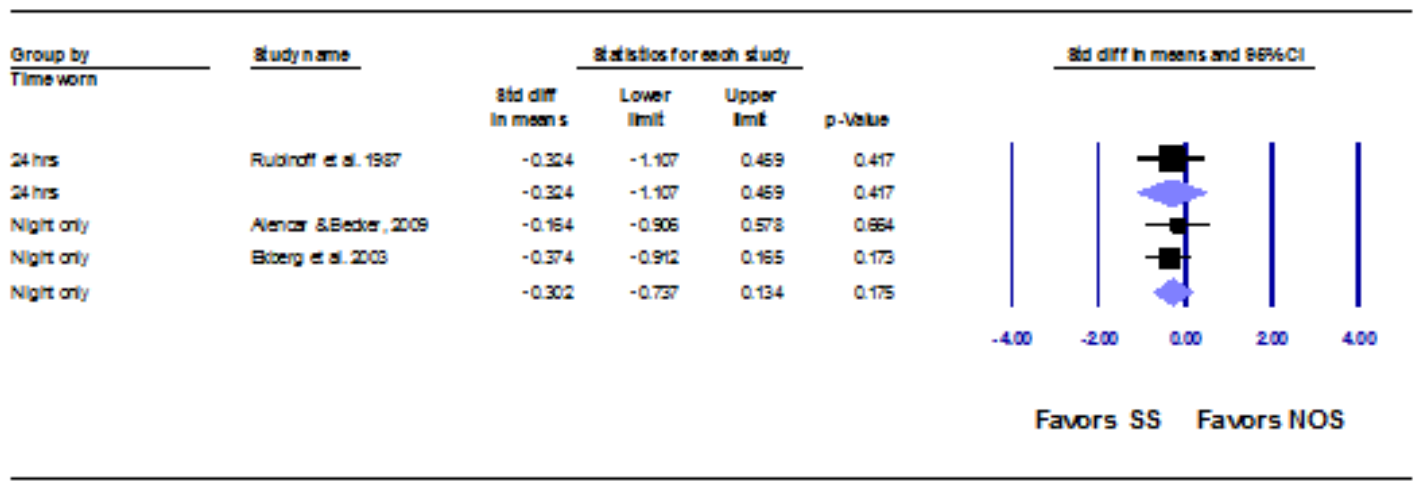

Figure 4. Stabilization splint versus non-occluding splint in myofascial patients: change in degree of tenderness of muscles (muscular palpation) with treatment. Fixed-effects model

\section{Number of responders to treatment}

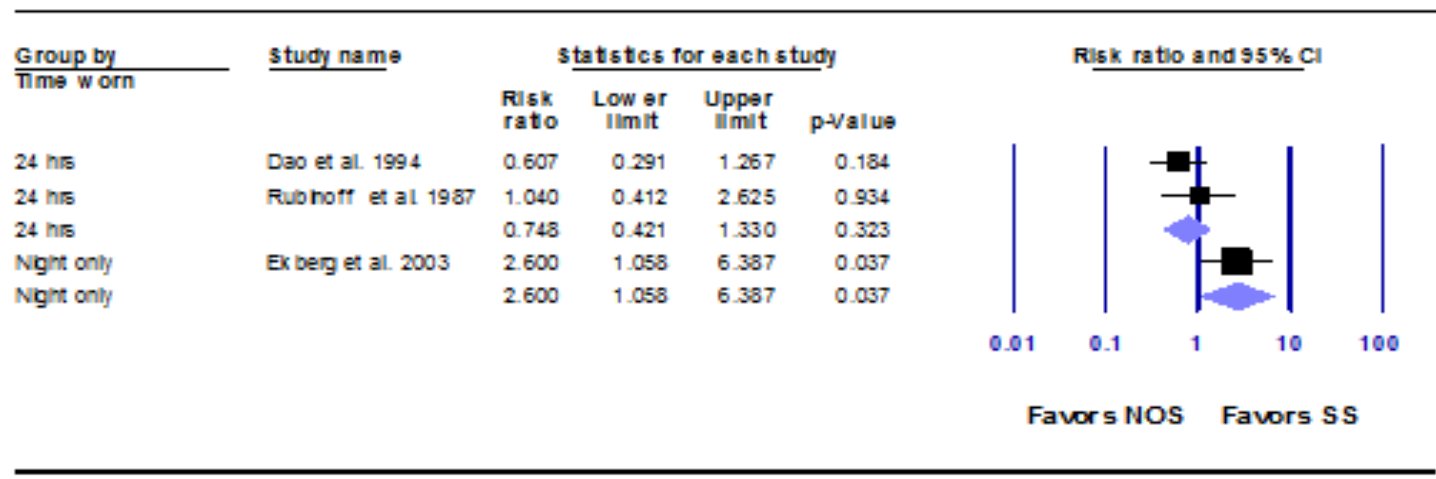

Figure 5. Responders to treatment defined as patients with a 50\% or more reduction of pain intensity (VAS). Fixed-effects model

\section{Number of patients with clicking at post-treatment}

\begin{tabular}{|c|c|c|c|c|c|}
\hline \multirow{2}{*}{$\frac{\text { Group by }}{\text { nime w or } n}$} & study na me & \multicolumn{4}{|c|}{ statistles for each study } \\
\hline & & $\begin{array}{l}\text { Rilsk } \\
\text { ratio }\end{array}$ & $\begin{array}{c}\text { Low er } \\
\text { Illmit }\end{array}$ & $\begin{array}{l}\text { Upper } \\
\text { IIImit }\end{array}$ & p-value \\
\hline $24 \mathrm{hrs}$ & Fub noff et al 1987 & 1.040 & 0.412 & 2.625 & 0.934 \\
\hline $24 \mathrm{hrs}$ & & 1.040 & 0.412 & 2.625 & 0.934 \\
\hline Nlght only & Ex berg et al 2003 & 1.182 & 0.634 & 2.204 & 0.599 \\
\hline Night only & & 1.182 & 0.634 & 2.204 & 0.599 \\
\hline
\end{tabular}

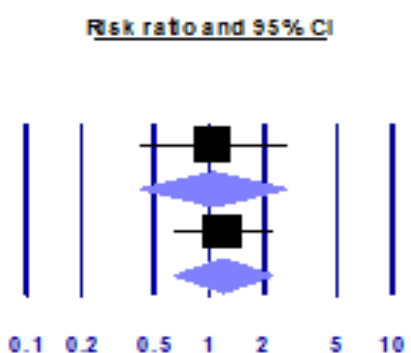

Favors SS Favors NOS

Figure 6. Number of patients with clicking at post-treatment visit. Fixed-effects model 
Clicking: Two studies reported clicking at post-treatment visit $[27,28]$. No significant differences were found in the number of patients with clicking at 6-10 weeks with the 24 hours SS [27] ( $\mathrm{RR}=1.040 ; 95 \% \mathrm{CI}=0.412$ to $2.625 ; \mathrm{p}$ $=.934)$, nor the splint worn only at night $[28](\mathrm{RR}=1.182$; $95 \% \mathrm{CI}=0.634$ to $2.204 ; \mathrm{p}=.599$ ) (Figure 6 ).

\section{Discussion}

Overall there were only eight eligible studies comparing full stabilization splints to non-occluding splints in myogenous TMD patients. Of those studies only five could be included in the meta-analyses. Three of the studies [26, $27,32]$ had patients wear their appliances for 24 hours a day and two $[11,28]$ of the studies patients wore only at night. Separate subgroup analyses were done for each of these two treatment options. The results of the meta-analyses have demonstrated a statistically significant reduction in pain intensity with flat plane occlusal splints in comparison to the non-occluding splint when worn at night only. A separate meta-analysis failed to demonstrate significance when comparing twenty-four hour use. This result is offset by the fact that there was only one study in the night-time use group [28] and only two in the 24-hour group [27, 32]. Subgroup analyses of the degree of tenderness to the muscles of mastication, number of responders (patients who reported a $50 \%$ reduction in pain) or patients with clicking were not statistically significant in either the night time or the 24-hour splint studies.

\subsection{Overall Completeness and Applicability of Evidence}

Studies were chosen based on specific inclusion criteria to keep the review focused and to control for extraneous variables. Many studies were rejected and only eight studies were eligible for qualitative analyses [11,26-32]. Due to missing data and heterogeneity of the outcomes reported, only five studies [11, 26-28, 32] could be included in the meta-analyses. Unfortunately, three of the studies [26, 27, 32] had the participants utilize their splints for 24 hours and two $[11,28]$ had the participants wear the splints at night only. This limited the ability to perform a strong meta-analysis.

\subsection{Quality of the Evidence}

The overall quality of the evidence was very low to low due to risk of bias (all the studies were unclear or high risk of bias), imprecision (small number of studies with small sample size) and suspected publication bias (with only one or two studies per subgroup analysis). (Table 3) Five of the outcomes (change in VAS pain, tenderness of muscles of mastication at palpation, number of responders to treatment and patients with clicking) could be analyzed by meta-analysis, however there were only one or two articles per outcome that could be included in each meta-analysis $[11,26-28,32]$ limiting the quality of the information.

Table 3. Quality of the evidence and summary of findings (GRADE). CI: Confidence interval; RR: Risk ratio;

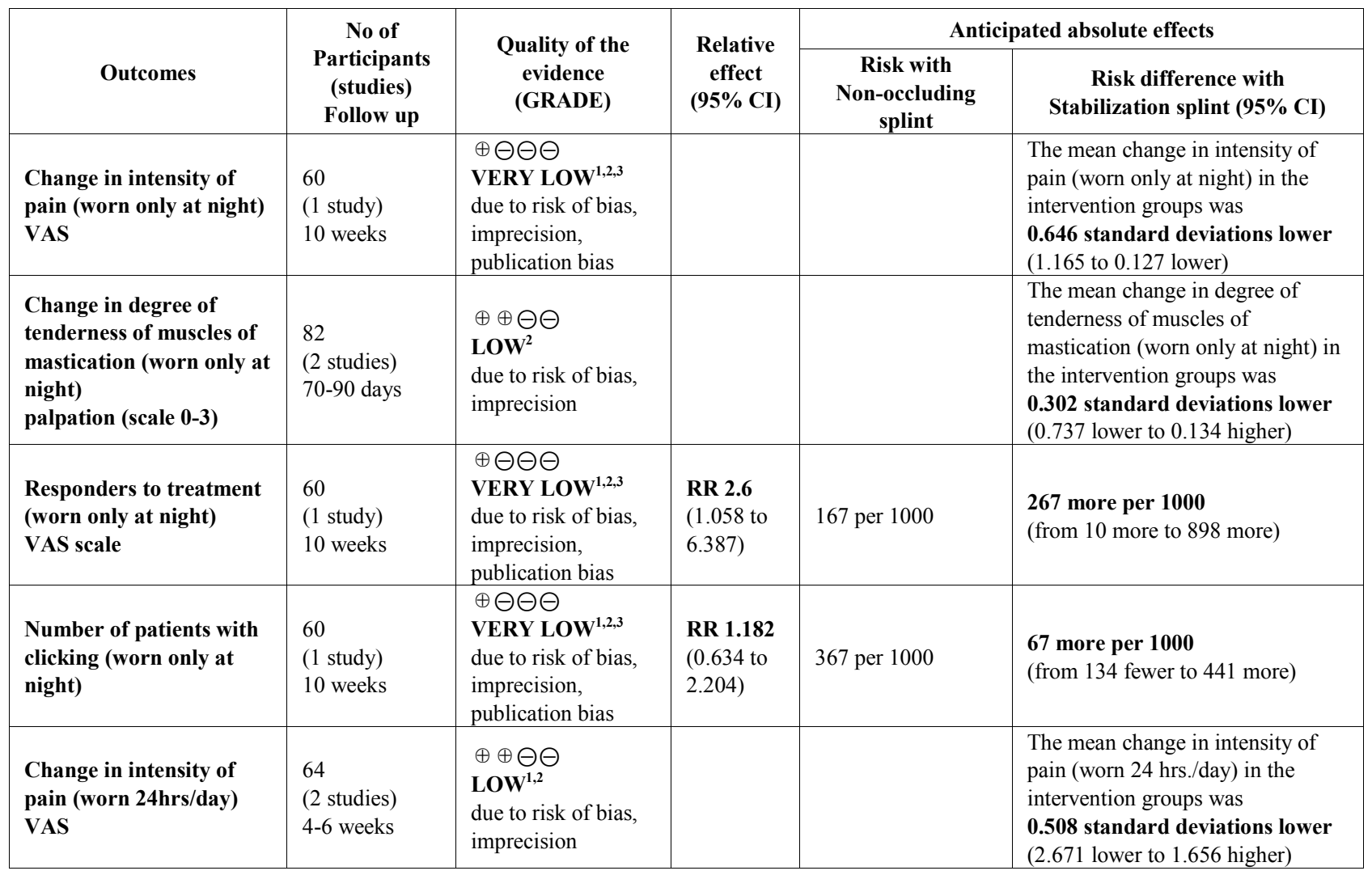




\begin{tabular}{|c|c|c|c|c|c|}
\hline $\begin{array}{l}\text { Change in degree of } \\
\text { tenderness of muscles of } \\
\text { mastication (worn } \\
\text { 24hrs/day) } \\
\text { palpation (scale 0-3) }\end{array}$ & $\begin{array}{l}26 \\
(1 \text { study) } \\
6 \text { weeks }\end{array}$ & $\begin{array}{l}\oplus \ominus \ominus \ominus \\
\text { VERY LOW } \\
\text { due to risk of bias, } \\
\text { imprecision, } \\
\text { publication bias }\end{array}$ & & & $\begin{array}{l}\text { The mean change in degree of } \\
\text { tenderness of muscles of } \\
\text { mastication (worn } 24 \mathrm{hrs} / \text { day) in the } \\
\text { intervention groups was } \\
\text { 0.324 standard deviations lower } \\
\text { ( } 1.107 \text { lower to } 0.459 \text { higher) }\end{array}$ \\
\hline $\begin{array}{l}\text { Responders to treatment } \\
\text { (worn } 24 \mathrm{hrs} / \text { day) } \\
\text { VAS scale }\end{array}$ & $\begin{array}{l}71 \\
(2 \text { studies }) \\
6-8 \text { weeks }\end{array}$ & $\begin{array}{l}\oplus \oplus \Theta \Theta \\
\mathbf{L O W} \mathbf{O W}^{1,2} \\
\text { due to risk of bias, } \\
\text { imprecision }\end{array}$ & $\begin{array}{l}\text { RR 0.748 } \\
(0.421 \text { to } \\
1.33)\end{array}$ & 471 per 1000 & $\begin{array}{l}119 \text { fewer per } 1000 \\
\text { (from } 272 \text { fewer to } 155 \text { more) }\end{array}$ \\
\hline $\begin{array}{l}\text { Number of patients with } \\
\text { clicking (worn } 24 \mathrm{hrs} / \text { day) }\end{array}$ & $\begin{array}{l}28 \\
(1 \text { study) } \\
6 \text { weeks }\end{array}$ & $\begin{array}{l}\oplus \ominus \ominus \ominus \\
\text { VERY LOW } \\
\text { due to risk of bias, } \\
\text { imprecision, } \\
\text { publication bias }\end{array}$ & $\begin{array}{l}\text { RR } 1.182 \\
(0.634 \text { to } \\
2.204)\end{array}$ & 385 per 1000 & $\begin{array}{l}70 \text { more per } 1000 \\
\text { (from } 141 \text { fewer to } 463 \text { more) }\end{array}$ \\
\hline \multicolumn{6}{|c|}{$\begin{array}{l}\text { GRADE Working Group grades of evidence: } \\
\text { High quality: Further research is very unlikely to change our confidence in the estimate of effect. Moderate quality: Further research is } \\
\text { likely to have an important impact on our confidence in the estimate of effect and may change the estimate. Low quality: Further research } \\
\text { is very likely to have an important impact on our confidence in the estimate of effect and is likely to change the estimate. Very low quality: } \\
\text { We are very uncertain about the estimate. }\end{array}$} \\
\hline \multicolumn{6}{|c|}{$\begin{array}{l}{ }^{1} \text { Unclear or high risk of bias studies } \\
{ }^{2} \text { Small number of studies with small sample size } \\
{ }^{3} \text { Only } 1 \text { included study }\end{array}$} \\
\hline
\end{tabular}

Studies which analyzed 24-hour use [26, 27, 32] were included due to the limited studies available for night time use $[11,28-31]$. All the papers included were determined to be unclear to high risk of bias and the number of studies and the number of participants were small. The grade or quality of evidence impacts our confidence in the results obtained and further research is needed to determine the effect of stabilization splints on myogenous temporomandibular disorders.

\subsection{Heterogeneity of the Review}

Studies included were limited to TMD myogenous pain only with the goal of keeping the diagnostic categories homogeneous. Participants were diagnosed by the criteria of the AAOP [5] in one study [11] or by the RDC/TMD [3] criteria in the other studies [26-32]. Papers with similar outcomes were pooled together in a meta-analysis. The number of studies which fell within the inclusion criteria was small and studies that had participants wear the splint for 24 hours $[26,27,32]$ were also included to increase the sample size. This caused some heterogeneity which we tried to control by adding a subgroup meta-analysis. Separate outcomes were analyzed individually in individual meta-analyses. The heterogeneity of the outcomes did limit the number of studies that were included in each of the meta-analyses.

\subsection{Agreements and Disagreements with Other Studies or Reviews}

It is difficult to make direct comparisons to prior reviews as available systematic reviews are based on the effects of occlusal splints on a mix of three TMD groups: muscle disorders, disc displacements and arthralgia conditions.
Also, our review focused on hard stabilization splints compared to non-occluding splints. Numerous RCTs, excluded in this review, compared splints of varying design (hard acrylic splints, soft splints, anterior splints) against different controls, which included other interventions from active treatment (such as other splint design, acupuncture, arthrocentesis, occlusal equilibration, cognitive therapy, medication) to no treatment or controls. Furthermore, there were significant variations in outcome acquisition and reporting in the studies reviewed by the SRs.

In a 1997 literature review, Major \& Nebbe [33] concluded that occlusal splint therapy is an effective treatment for patients suffering masticatory muscle pain but not joint pain. Forssell et al. [34], in their qualitative systematic review in 1999 noted that the quality of the trials available for study was low and that the estimation of efficacy was weak and only suggestive conclusions could be drawn. With these facts in mind, the authors did conclude that splint therapy was found superior when compared to three controls- ultrasound, palliative treatment and palatal splint.

Two systematic reviews $[35,36]$ including myogenous and arthralgia TMD patients, reported that there were no significant differences between the use of a stabilization splint and non-occluding splints for any of the outcomes measured. Two studies [26, 27] in these reviews were also evaluated in this review. Our meta-analysis that included these two articles yielded similar conclusions. Kreiner et al. [35] found that stabilization splints work better than a wait-list control but not better than a credible placebo therapy. It was concluded that the behavioral effect of an occlusal appliance likely is the result of jaw function changes induced by both wearing a device and being in the study.

Türp et al. [37] evaluated the effect of stabilization 
splints on muscle related pain in comparison to various controls. The authors evaluated three studies [26-28] that were also included in our review. It was reported that the search demonstrated inconsistencies that exist among different authors about the diagnosis "muscle pain". This variability is reflected in the number of diagnostic systems that have been proposed over the past decades for classifying the different subsets of TMDs. The authors concluded that evidence at the time was inconclusive about the question of whether the observed improvement during and after stabilization therapy is greater than the one achieved by a non-occluding palatal appliance (i.e., a "placebo" splint).

A meta-analysis of seven studies [10] with 385 patients with varying TMD conditions reported that a hard stabilization appliance was found to improve TMD pain compared to a non-occluding appliance. The overall odds ratio $(\mathrm{OR})$ of 2.46 was statistically significant $(\mathrm{P}=.001)$. Fricton et al. [10] concluded that hard stabilization appliances, when adjusted properly, have good evidence of modest efficacy in the treatment of TMD pain compared to non-occluding appliances and to no treatment. Other types of appliances, including soft stabilization appliances, anterior positioning appliances, and anterior bite appliances, have some RCT evidence of efficacy in reducing TMD pain.

List and Axelsson [9] evaluated the methodological quality of each identified SR using two measurement tools: the assessment of multiple systematic reviews (AMSTAR) and level of research design scoring. They concluded that there is some evidence that the following can be effective in alleviating TMD pain: occlusal appliances, acupuncture, behavioral therapy, jaw exercises, postural training, and some pharmacological treatments. They noted that one limitation of most of the reviewed SRs was that the considerable variation in methodology between the primary studies made definitive conclusions impossible.

Two more recent systematic reviews [38, 39] analyzed studies with varying classifications of TMD conditions that were treated with different splint designs against various controls. Ebrahim et al. [38] reviewed 11 studies involving a total of 455 patients. Only one study [26] was present in both our review and theirs. A meta-analysis performed showed that splint therapy had a substantial effect on reducing pain compared to minimal or no treatment $(\mathrm{SMD}=$ $-0.93 ; 95 \% \mathrm{CI},-1.33$ to $-0.53 ; \mathrm{p}<.01)$. Zhang et al. [39] reviewed 13 studies with 538 patients. They reported a significant difference in the changes in level of perceived pain [VAS] $(\mathrm{MD}=2.02,95 \% \mathrm{CI}[1.55,2.49], \mathrm{I} 2=0 \%$, $\mathrm{P}=0.558)$ and subgroup analysis showed that patients with TMD in the splint therapy group experienced a significant decrease in pain as compared to control (MD $=2.00,95 \%$ CI $[1.50,2.51]$, I2 $=34.5 \%, \mathrm{P}=0.217)$.

\section{Conclusions}

There is poor but significant evidence that flat plane occlusal splints are more effective than non-occluding splints when evaluating pain intensity when worn during the night only. This significance was not evident with other outcomes studied by the articles reviewed or when splints were worn for 24 hours a day. Historically and currently, clinicians have relied on splints for the treatment of painful TMD. There are numerous articles that tout the effectiveness of splints to relieve pain in TMD patients but the management approach may be considered empirical in nature until stronger research is performed. Because stabilization splints are part of a conservative, inexpensive and reversible treatment regimen, continued use for myogenous TMD remains a viable option. Additional research with larger sample sizes, more specific groupings and longer term follow ups are necessary to provide a definitive recommendation.

In the process of performing this systematic review, the authors encountered a significant number of potential relevant articles that covered the subject of treatment of TMD with stabilizing splint. Only eight RCT's were used for study. Several SRs have explored the question of the efficacy of this treatment approach but definitive recommendations for the use of stabilizing splints remains elusive. The authors of these previous SRs have cited variability in RCT methodology has limited synthesis of meta-analysis and thus the ability to provide strong recommendations for the use of the stabilizing splints. To answer the question of splint efficacy, we suggest RCT's that compare flat plane splint versus a non-occluding splint for the treatment of patients within a specific diagnostic category (myalgia, painful disc displacement with reduction, arthritis, etc.) and recording a specific outcome (reduction in VAS) to attain standardization. The most current taxonomy for TMD, the DC/TMD [3] can be utilized for the placement of appropriate patients into appropriate diagnostic groups. This classification system was developed for practical use in the clinical setting and is an ideal reference for research design. Just as specific diseases require specific approaches for predictable resolution, there is prudence in isolating the TMD entity to be studied to achieve confident recommendations from clinical trials.

To achieve standardization for outcome measures and reporting, the core outcomes outlined by the Initiative on Methods, Measurement, and Pain Assessment in Clinical Trials (IMMPACT)[40] should be considered when designing chronic pain clinical trials. These core outcome domains included (1) pain; (2) physical functioning; (3) emotional functioning; (4) participant ratings of improvement and satisfaction with treatment; (5) symptoms and adverse events; and (6) participant disposition. Of relevance in a splint efficacy study would be the core outcome of pain and participant rating of improvement from the intervention.

Further research studies are needed to confirm our results that flat plane splints worn at night are effective in the reduction of pain. In addition to minimizing bias, improving 
blinding and collecting larger sample size to strengthen the confidence of the results obtained, standardizing designs and clearly defining outcome measures and reporting would enhance the ability to compare results and pool data for synthesis (meta-analysis), to allow confident recommendations for splint efficacy.

\section{Acknowledgements}

The authors of this review would like to thank Dr. Margarita Zeichner-David, PhD at Herman Ostrow School of Dentistry of USC for help with editing and formatting the manuscript.

\section{REFERENCES}

[1] R. de Leeuw, "Orofacial Pain: Guidelines for Assessment, Diagnosis and Management," in Orofacial Pain: Guidelines for Assessment, Diagnosis and Management 5th Edition, 2013.

[2] W. Maixner, L. Diatchenko, R. Dubner, R. B. Fillingim, J. D. Greenspan, C. Knott, R. Ohrbach, B. Weir, and G. D. Slade, "Orofaciaol Pain Prospective Evaluation and Risk Assessment Study - The OPPERA study," J. Pain, vol. 12, no. 11, p. T4-T11.e2, 2012.

[3] E. Schiffman, R. Ohrbach, E. Truelove, J. Look, G. Anderson, J.-P. Goulet, T. List, P. Svensson, et al., "Diagnostic Criteria for Temporomandibular Disorders (DC/TMD) for Clinical and Research Applications: Recommendations of the International RDC/TMD Consortium Network* and Orofacial Pain Special Interest Group $\dagger$.," J. oral facial pain headache, vol. 28, no. 1, pp. 6-27, 2014.

[4] L. Dworkin, Samuel F \& Le Resche, "Research diagnostic criteria for temporomandibular disorders," J. Craniomandib. Disord., vol. 6, no. 4, pp. 1-29, 1992.

[5] J. P. Okeson, Orofacial Pain: Guidelines for Assessment, Diagnosis, and Management. Quintessence Publishing Company, Incorporated, 1996.

[6] T. List and R. H. Jensen, "Temporomandibular disorders: Old ideas and new concepts," vol. 0, no. 0, pp. 1-13, 2017.

[7] T. T. Dao and G. J. Lavigne, "Oral splints: the crutches for temporomandibular disorders and bruxism?" Crit. Rev. Oral Biol. Med., vol. 9, no. 3, pp. 345-61, Jan. 1998.

[8] G. D. Klasser and C. S. Greene, "Oral appliances in the management of temporomandibular disorders.," Oral Surg. Oral Med. Oral Pathol. Oral Radiol. Endod., vol. 107, no. 2, pp. 212-23, Feb. 2009.

[9] T. List and S. Axelsson, "Management of TMD: evidence from systematic reviews and meta-analyses," J. Oral Rehabil., vol. 37, no. 6, pp. 430-451, Jun. 2010.

[10] J. Fricton, J. O. Look, E. Wright, F. G. P. Alencar, H. Chen, M. Lang, W. Ouyang, A. M. Velly, et al., "Systematic review and meta-analysis of randomized controlled trials evaluating intraoral orthopedic appliances for temporomandibular disorders.," J. Orofac. Pain, vol. 24, no. 3, pp. 237-254, 2010.

[11] F. Alencar, A. Becker, F. Alencar Jr., and A. Becker, "Evaluation of different occlusal splints and counselling in the management of myofascial pain dysfunction.," J. Oral Rehabil., vol. 36, no. 2, pp. 79-85, Mar. 2009.

[12] J. Higgins and S. (editors) Green, "Cochrane Handbook for Systematic Reviews of Interventions Version 5.1.0 [updated March 2011].," 2011.

[13] W. Cochran, "The combination of estimated from different experiments.," Biomimetrics, vol. 10, pp. 101-129, 1954.

[14] J. Higgins and S. Thompson, "Quantifying heterogeneity in a meta-analysis," Stat. Med., vol. 21, pp. 1539-1558, 2002.

[15] K. Nagata, H. Maruyama, R. Mizuhashi, S. Morita, S. Hori, T. Yokoe, and Y. Sugawara, "Efficacy of stabilisation splint therapy combined with non-splint multimodal therapy for treating RDC/TMD axis I patients: a randomised controlled trial," J. Oral Rehabil., vol. 42, no. 12, pp. 890-899, Dec. 2015.

[16] A. Gavish, E. Winocur, Y. S. Ventura, M. Halachmi, and E. Gazit, "Effect of stabilization splint therapy on pain during chewing in patients suffering from myofascial pain.," J. Oral Rehabil., vol. 29, no. 12, pp. 1181-6, Dec. 2002.

[17] F. A. M. Al Quran and M. S. Kamal, "Anterior midline point stop device (AMPS) in the treatment of myogenous TMDs: comparison with the stabilization splint and control group.," Oral Surg. Oral Med. Oral Pathol. Oral Radiol. Endod., vol. 101, no. 6, pp. 741-7, Jun. 2006.

[18] M. Doepel, M. Nilner, E. Ekberg, and Y. Le Bell, "Long-term effectiveness of a prefabricated oral appliance for myofascial pain," J. Oral Rehabil., vol. 39, no. 4, pp. 252-260, Apr. 2012

[19] C. S. Greene and D. M. Laskin, "Splint therapy for the myofascial pain--dysfunction (MPD) syndrome: a comparative study.," J. Am. Dent. Assoc., vol. 84, no. 3, pp. 624-8, Mar. 1972.

[20] M. Al-Saad and R. F. Akeel, "EMG and pain severity evaluation in patients with TMD using two different occlusal devices.," Int. J. Prosthodont., vol. 14, no. 1, pp. 15-21, Jan. 2001.

[21] E. C. Ekberg and M. Nilner, "Treatment outcome of shortand long-term appliance therapy in patients with TMD of myogenous origin and tension-type headache.," J. Oral Rehabil., vol. 33, no. 10, pp. 713-21, Oct. 2006.

[22] D. A. G. Gonçalves, C. M. Camparis, J. G. Speciali, S. M. Castanharo, L. T. Ujikawa, R. B. Lipton, M. E. Bigal, D. A. G. Goncalves, et al., "Treatment of comorbid migraine and temporomandibular disorders: a factorial, double-blind, randomized, placebo-controlled study.," J. Orofac. Pain, vol. 27, no. 4, pp. 325-35, Jan. 2013.

[23] R. W. Wassell, N. Adams, and P. J. Kelly, "Treatment of temporomandibular disorders by stabilising splints in general dental practice: results after initial treatment.," Br. Dent. J., vol. 197, no. 1, pp. 35-41-1, Jul. 2004.

[24] R. W. Wassell, N. Adams, P. J. Kelly, and H. Mfph, "The treatment of temporomandibular disorders with stabilizaing splints in general dental practice - One year follow up," J. Am. 
Dent. Assoc., vol. 137, no. August, pp. 1089-98-9, Aug. 2006.

[25] M. Kuttila, Y. Le Bell, E. Savolainen-Niemi, S. Kuttila, and P. Alanen, "Efficiency of occlusal appliance therapy in secondary otalgia and temporomandibular disorders.," Acta Odontol. Scand., vol. 60, no. 4, pp. 248-54, Aug. 2002.

[26] T. T. T. Dao, G. J. Lavigne, A. Charbonneau, J. S. Feine, and J. P. Lund, "The efficacy of oral splints in the treatment of myofascial pain of the jaw muscles: A controlled clinical trial," Pain, vol. 56, no. 1, pp. 85-94, Jan. 1994.

[27] M. S. Rubinoff, A. Gross, and W. D. McCall, "Conventional and nonoccluding splint therapy compared for patients with myofascial pain dysfunction syndrome.," Gen. Dent., vol. 35, no. 6, pp. 502-6, Jan. 1987.

[28] E. Ekberg, M. Nilner, and D. Vallon, "The efficacy of occlusal appliance therapy in patients with temporomandibular disorders of mainly myogenous pain. A randomized-controlled trial in a short-term perspective abstract,” J. Oral Rehabil., vol. 17, no. 9, p. 874, 2003.

[29] E. Ekberg and M. Nilner, "Treatment outcome of appliance therapy in temporomandibular disorder patients with myofascial pain after 6 and 12 months.," Acta Odontol. Scand., vol. 62, no. 6, pp. 343-9, Dec. 2004.

[30] K. G. Raphael and J. J. Marbach, "Widespread pain and the effectiveness of oral splints in myofascial face pain.," J. Am. Dent. Assoc., vol. 132, no. 3, pp. 305-16, Mar. 2001.

[31] K. G. Raphael, J. J. Marbach, J. J. Klausner, M. F. Teaford, and D. K. Fischoff, "Is bruxism severity a predictor of oral splint efficacy in patients with myofascial face pain?," J. Oral Rehabil., vol. 30, no. 1, pp. 17-29, Jan. 2003.

[32] F. Zhang, X. Wang, J. Dong, J. Zhang, and Y. Lu, "Effect of occlusal splints for the management of patients with myofascial pain: a randomized, controlled, double-blind study," Chin. Med. J. (Engl)., vol. 126, no. 12, pp. 22702275, Jun. 2013.
[33] P. W. Major and B. Nebbe, "Use and effectiveness of splint appliance therapy: review of literature.," Cranio, vol. 15, no. 2, pp. 159-66, Apr. 1997.

[34] H. Forssell, E. Kalso, P. Koskela, R. Vehmanen, P. Puukka, and P. Alanen, "Occlusal treatments in temporomandibular disorders: a qualitative systematic review of randomized controlled trials.," Pain, vol. 83, no. 3, pp. 549-60, Dec. 1999.

[35] M. Kreiner, E. Betancor, and G. T. Clark, "Occlusal stabilization appliances. Evidence of their efficacy.," J. Am. Dent. Assoc., vol. 132, no. 6, pp. 770-7, Jun. 2001.

[36] M. Z. Al-Ani, S. J. Davies, R. J. M. Gray, P. Sloan, and A. M. Glenny, "Stabilisation splint therapy for temporomandibular pain dysfunction syndrome.," Cochrane database Syst. Rev., no. 1, p. CD002778, Jan. 2004.

[37] J. C. Türp, F. Komine, and A. Hugger, "Efficacy of stabilization splints for the management of patients with masticatory muscle pain: a qualitative systematic review.," Clin. Oral Investig., vol. 8, no. 4, pp. 179-95, Dec. 2004.

[38] S. Ebrahim, L. Montoya, J. W. Busse, A. Carrasco-Labra, and G. H. Guyatt, "The effectiveness of splint therapy in patients with temporomandibular disorders: a systematic review and meta-analysis.," J. Am. Dent. Assoc., vol. 143, no. 8, pp. 847-57, Aug. 2012.

[39] C. Zhang, J.-Y. Wu, D.-L. Deng, B.-Y. He, Y. Tao, Y.-M. Niu, M.-H. Deng, C. Zhang, J.-Y. Wu, D.-L. Deng, B.-Y. He, Y. Tao, Y.-M. Niu, and M.-H. Deng, "Efficacy of splint therapy for the management of temporomandibular disorders: a meta-analysis," Oncotarget, vol. 7, no. 51, pp. 8404384053, 2016.

[40] D. C. Turk, R. H. Dworkin, R. R. Allen, N. Bellamy, N. Brandenburg, D. B. Carr, C. Cleeland, R. Dionne, et al., "Core outcome domains for chronic pain clinical trials: IMMPACT recommendations," vol. 106, pp. 337-345, 2003. 